\title{
EMPREENDEDORISMO JOVEM: PERFIL E MOTIVAÇÕES DE EMPREENDEDORES EM ARACAJU, SERGIPE
}

\author{
YOUTH ENTREPRENEURSHIP: PROFILE AND MOTIVATIONS OF ENTREPRENEURS IN ARACAJU, \\ SERGIPE
}

DOI: http://dx.doi.org/10.12712/rpca.v6i4.227

\section{Felipe Carvalhal}

carvalhalfelipe@gmail.com

Centro de Ciências Sociais Aplicadas - Universidade Federal de Sergipe (UFS) - Aracaju - SE, Brasil

\section{Ana Luísa Leão}

ana cleao@yahoo.com

Centro de Ciências Sociais Aplicadas - Universidade Federal de Sergipe (UFS) - Aracaju - SE, Brasil

\section{Rivanda Meira Teixeira}

rivandateixeira@gmail.com

Centro de Ciências Sociais Aplicadas - Universidade Federal de Sergipe (UFS) - Aracaju - SE, Brasil

\section{Resumo}

Apesar da participação significativa dos jovens na criação de empresas e dos mecanismos para incentivá-los, pouco se conhece sobre as especificidades de jovens empreendedores. Este estudo teve como objetivo geral analisar o perfil e as motivações dos empreendedores jovens de Aracaju, Sergipe. Especificamente pretende delinear o perfil desses jovens que empreendem, identificar as sua motivação para a abertura do negócio e ainda descrever as empresas criada por esses empreendedores. Esta pesquisa classifica-se como quantitativa, descritiva e de corte transversal. A estratégia de pesquisa adotada foi survey, utilizando-se de um questionário estruturado como instrumento de coleta de dados. Foram pesquisados 27 jovens empreendedores, entre 18 e 34 anos, da cidade de Aracaju, com adoção de critério amostral não probabilístico. Como principais resultados foi possível destacar que os empreendedores jovens de Aracaju são na sua maioria do sexo masculino, idade entre 25 e 34 anos, alto grau de educação formal, renda familiar elevada, solteiros e não são associados ao CJE. Verificou-se ainda que estes jovens criam seu negócios por oportunidade, motivados pela busca de realização pessoal, para aproveitar uma oportunidade de mercado ou para alcançar a independência financeira. As empresas constituídas por eles são de pequeno porte, do setor de serviço, com a participação de sócios e o capital inicial é próprio, da família ou do sócio.

Palavras-chave: Empreendedorismo jovem. Perfil de empreendedores. Motivações.

\section{Abstract}

Despite the significant participation of young people in the creation of companies and mechanisms to encourage them, little is known about the specific characteristics of young entrepreneurs. This study aimed to analyze the profile and motivations of young entrepreneurs of Aracaju, Sergipe. Specifically intended to delineate the profile of these young entrepreneurs, identify their motivation for opening the business and describe the businesses created by them. This research is classified as quantitative, descriptive and cross-sectional. The research strategy adopted was survey, using a structured questionnaire as a tool for data collection. Were surveyed 27 young entrepreneurs between 18 and 34 years old, from Aracaju adopting non-probabilistic sampling criteria. As the main results it was possible to highlight that the young entrepreneurs of Aracaju are mostly male, aged between 25 and 34 years, high degree of formal education, high household incomes, single and not linked to the CJE. It was also found that these young people create their business looking for opportunities, motivated by personal fulfillment, to take advantage of a market opportunity or to achieve financial independence. The businesses created are small, from the service sector, with partners and the the initial capital is 
Empreendedorismo jovem: perfil e motivações de empreendedores em Aracaju, Sergipe

own, from the family or partner.

Keywords: Youth entrepreneurship. Entrepreneur profile. Motivation. 


\section{Introdução}

Pela sua importância econômica e social o empreendedorismo vem sendo objeto crescente de estudos em diversos países e também no Brasil, como apontam Licht, Oliveira e Ventura (2007). Os autores Armond e Nassif (2009) corroboram essa ideia revelando que os temas voltados ao estudo do empreendedor conquistam uma pauta de inquestionável relevância, uma vez que estes atores exercem um papel fundamental na visão, condução e atuação junto aos negócios; mas salientam que ainda há muito que se pesquisar.

Do mesmo modo, diferentes abordagens sobre o empreendedor é encontrada na literatura, no entanto, os pesquisadores concordam que ele é importante e até vital para economia, visto que a atividade empreendedora inova e traz riqueza, gera emprego e renda, e atende a necessidades sociais (Global Entrepreneurship Monitor - GEM, 2011; GIMENEZ; INACIO JUNIOR, 2002). Morrison (1998) observa que o empreendedor é o coração dos empreendimentos. Já Dornelas (2001) diz que o empreendedor é um profissional que faz a diferença por ser considerado visionário, otimista e apaixonado pelo que faz. Trata-se de uma pessoa com competências diferenciadas, capaz de criar valor para a sociedade na qual se encontra inserido, buscando soluções para melhorar a vida das pessoas.

Somado a isso, tem-se os dados apresentados no GEM (2011), onde foi percebido que, em 2011 no Brasil, 27 milhões de brasileiros, 26,9\% da população da adulta (18 a 64 anos) eram proprietários ou administradores de algum negócio, independente do porte, sofisticação ou tempo de mercado. Observou-se ainda que houve uma queda no percentual daqueles empreendedores em estágio inicial (TEA), aquelas com até 3 anos e meio de criação, em relação ao ano anterior de 17,5\% (GEM, 2011) para atuais 14,89\%, ou seja 15 milhões de pessoas (GEM, 2011), destaca-se o papel do empreendedor jovem, aquele com idade entre 18 e 34 anos, que representou 51,99\% dos empreendedores do Brasil em estágio inicial, sendo assim mais numerosos do que as outras faixas etárias. Uma das hipóteses levantadas pela pesquisa para esta queda é alta demanda por mão de obra de qualidade, o que acarreta aumento dos salários dos profissionais, os quais acabam adiando o projeto de empreender.

Ainda segundo o relatório da pesquisa GEM (2011), a sociedade pode se beneficiar de empreendedores de todas as faixas etárias. Num extremo as pessoas jovens com ideias holísticas, perspectivas diferentes de observar o ambiente e formação diferente de seus pais. No outro, as pessoas mais velhas com sua experiência, contatos e o capital que acumularam durante sua longa carreira. Apesar de a atividade empreendedora ser mais dinâmica nas idades intermediárias, os formuladores de políticas públicas não devem perder de vista o potencial empreendedor dos extremos.

Apesar da participação significativa dos jovens na criação de empresas e dos mecanismos colocados em prática para incentivá-los a fazer ainda mais, há um problema a ser considerado: pouco se conhece sobre as especificidades do jovem empreendedor (LORRAIN; LAFERTÉ, 2006; BORGES; FILION; SIMARD, 2008). Dessa forma, poucos são os autores, no campo do empreendedorismo, que se preocupam em analisar especificamente os jovens. Além do papel que eles já realizam na criação de novos negócios, é possível que nos próximos anos um número ainda maior passe a escolher, como opção de carreira, ser dono da própria empresa. Isso porque o incentivo ao empreendedorismo juvenil é uma das estratégias que os agentes públicos estão utilizando, de forma crescente, para reduzir o desemprego entre os jovens e inseri-los no mercado de trabalho (RIVERIN; JEAN, 2005; OCDE, 2005).

Este estudo tem como objetivo geral analisar o perfil e as motivações dos empreendedores 
jovens de Aracaju, Sergipe. Especificamente pretende delinear o perfil desses jovens empreendedores; identificar as motivações para a abertura do negócio e ainda descrever as empresas criadas por esses destes empreendedores.

\section{Empreendedorismo}

Considerado um fator chave para o crescimento econômico, criação de empregos e estabilidade social, o empreendedorismo possui enorme relevância no desenvolvimento dos países. Viet et al. (2009) destacam que os indivíduos empreendedores impulsionam a economia, provendo novos bens de consumo e métodos inovadores de produção. Martinelli e Fleming (2010) apontam essas razões pela qual este tema tem recebido atenção especial nos últimos anos junto à comunidade científica.

Apesar de muitos considerarem o empreendedorismo como um fenômeno recente, Dutra e Previdelli (2003) afirmam que manifestações empreendedoras remontam à época das práticas mercantis, como as dos fenícios e árabes, as quais proporcionaram o crescimento e desenvolvimento econômico da maioria dos continentes civilizados. Segundo Honma e Teixeira (2011), nos últimos anos, o campo do empreendedorismo cresceu e expandiu-se além de suas fronteiras, tornando-se destaque em praticamente todas as áreas das ciências humanas e gerenciais.

Muitos autores caracterizam o empreendedorismo como um fenômeno multifacetado e multidisciplinar. Para Lopez Júnior e Souza (2008), a definição da atividade empreendedora ou dos comportamentos que a compõem, normalmente é complexa, e geralmente vem acompanhada de um grande número de indicadores como inovação, iniciativa, criatividade, propensão a correr risco, comprometimento, persistência, entre outros. Com uma visão complementar encontram-se Boava e Macedo (2006), ao descreverem o empreendedorismo como sendo um fenômeno social que traz consigo implicações de naturezas psicológicas, sociais, culturais ou econômicas.

Dentre os inúmeros conceitos sobre empreendedorismo mencionados na literatura, destacase o adotado pelo GEM (2008), onde o empreendedorismo é observado como qualquer tentativa de criação de um novo negócio ou novo empreendimento. Nesta conceituação podem ser consideradas, por exemplo, atividade autônoma, nova empresa, ou a expansão de empreendimento existente, seja por um indivíduo, grupos de indivíduos ou por empresas já estabelecidas. Sendo assim, é possível aferir que o empreendedorismo, é, portanto, um conceito dinâmico no qual o empreendedor destaca-se ou surge quando novas situações aparecem, novas decisões são tomadas, novos rumos são escolhidos, visto a melhora de seu negócio.

\section{Empreendedorismo jovem}

Falar sobre o empreendedorismo jovem ainda é um desafio, principalmente porque as pesquisas sobre o referido tema ainda são escassas. Porém, o que se pode afirmar é que os jovens são um recurso importante para o desenvolvimento de uma sociedade, e, por isso, precisam ser valorizados.

Observa-se que, no período de 1992 a 2006, a participação do jovem brasileiro no Mercado de Trabalho, apresentou uma queda de 4,9\% (25\% para 20,1\%), valor mais elevado que no total da População Economicamente Ativa (PEA), que foi reduzida de 69,7\% para 67,9\%. Essa diferença nas taxas é um forte indício de que os jovens estão enfrentando um cenário de maior dificuldade de inserção no mercado de trabalho. Isto pode ser percebido na taxa de 
desemprego entre jovens no Brasil, que é 3,2 vezes superior à registrada entre adultos. Enquanto a taxa de desemprego das pessoas com 25 anos ou mais subiu de 4,3\% para 5,6\%, a dos jovens cresceu de 11,7\% para 18\% (BULGACOV et al., 2011).

Minola e Criouco (2011) consideram que a intervenção política é essencial devido ao efeito prejudicial que a juventude desempregada tem sobre o nível de bem-estar dentro da sociedade. Os autores mencionam ainda que muitos jovens que procuram emprego, especialmente aqueles entre 16 e 35 anos, possuem atitudes positivas em relação ao empreendedorismo, mas que é extremamente baixo o número dos que se engajam numa carreira empresarial, criando seu próprio negócio.

Zouain, Oliveira e Barone (2007) destacam que o empreendedorismo, especialmente com foco no jovem, surge como um tema crucial na agenda presente do desenvolvimento socioeconômico brasileiro, pois afeta diretamente o processo de inclusão dos jovens no mercado de trabalho. Contudo, Schoof (2006) aponta que os representantes da população pouco se têm esforçado para encarar o empreendedorismo numa perspectiva da juventude; segundo ele, os jovens em sua maioria estão sendo tratados como parte da população adulta em geral, enquanto isso suas necessidades específicas e seu potencial para empreender estão sendo deixados de mão, em detrimento de sua contribuição para o desenvolvimento econômico e progresso social. Ainda conforme o mesmo autor há carência de estudos específicos sobre o assunto.

Apesar das dificuldades no financiamento para iniciar um negócio ser uma grande barreira par as jovens iniciarem seus negócios, os estudiosos afirmam que a mais influente delas é a falta de conhecimentos técnicos necessários e capacidades gerencias, o que pode ser um resultado de uma baixa exposição precoce à educação empreendedora (MINOLA E CRIOUCO, 2011).

Um fato curioso é que pesquisas sobre empreendedorismo jovem vêm revelando a importância deste empreendedor e aumento de sua participação na economia. Em 2008, os dados já revelavam que os jovens vinham ampliando a sua participação no universo do empreendedor brasileiro (GEM, 2011), e em 2011 as taxas de empreendedorismo naqueles que tem entre 18 e 24 anos ficou em 12,82\%, enquanto que de 15 a 34 anos 17,85\%, sendo esta última a maior taxa entre todas as faixas etárias pesquisadas (GEM, 2011).

Em 2010, os jovens entre 18 e 34 anos representaram 56,9\% dos empreendedores do Brasil (GEM 2010). Já ano 2011 este número caiu para 51,99\%, o que não deixa de ter sua importância, visto que os jovens ainda são maioria entre os empreendedores(GEM, 2011). 0 GEM (2011) ainda destaca que o jovem brasileiro possui uma característica de assumir riscos, item apontado por muitos autores como inerente a atividade empreendedora, o que favorece a existência de tantos empreendedores jovens.

Teixeira et. al (2001), assim como Zouain, Oliveira e Barone (2007), destacam que a alta taxa de jovens empreendedores assinala a importância de ações específicas para esse grupo e aponta a necessidade de desenvolvimento de políticas públicas. Para estes estudiosos, os jovens que empreendem estão entrando com muita força no mercado, e muito pouco se conhece sobre as especificidades desse grupo de empreendedores.

Como o estudo do tema ainda é recente, Machado e Gimenez (2000) destacam uma tendência existente entre os empreendedores jovens no sentido de buscar modelos em outros empreendedores que sirvam como referência e identificação. Segundo os autores, o perfil 
destes jovens ainda não de conhecimento amplo.

Com o propósito de tratar o perfil sobre esses jovens empreendedores, estudiosos como Motta e Trevissan (2003); Zouain, Oliveira e Barone (2007); Borges, Filion e Simard (2008); Bulgacov et al. (2011), dentre outros, ao realizarem suas pesquisas, datadas entre os anos de 2003 até 2011, e feitas tanto no Brasil como no exterior, em alguns casos, observaram alguns traços desses jovens. Os resultados obtidos com as pesquisas foram pontuados conforme $o$ que se deseja.

Foram ressaltadas informações sobre participação em órgãos de fomento ao empreendedorismo, sexo, idade, estado civil, renda familiar, motivações para a abertura do negócio, formação escolar, participação na Confederação Nacional dos Jovens Empresários (CONAJE) versus formação escolar, tempo de vida das empresas, recursos financeiros para a criação da empresa, etc.

Quando de se trata deste jovem estar associado ou participar de algum órgão que fomente a disseminação do empreendedorismo, a exemplo da Conselho Nacional de Jovens Empreendedores -CONAJE ou Conselho de Jovens Empreendedores -CJE, sabe-se que o seu envolvimento ainda acontece de forma tímida. Foi isto que mostrou o estudo de Zouain, Oliveira e Barone (2007), com associados e não associados da CONAJE, dimensionado para 1.500 associados e 330 não associados, ou seja, 81,97\% para associados e 18,03\% para não associados.

Em relação ao sexo do jovem empreendedor, o resultado do estudo de Lima Filho, Sproesser e Martins (2009) mostrou igualdade entre os respondentes de Cuiabá-Mato Grosso. Na contramão deste resultado, encontram-se aqueles obtidos com a pesquisa de Ribeiro e Teixeira (2012), elas constataram em seu estudo de casos que os empreendedores jovens de Sergipe abordados em sua pesquisa também são do sexo masculino. Motta e Trevissan (2003), em pesquisa realizada com empreendedores vinculados à Associação de Jovens Empresários de Santa Maria/RS, verificarem que a maioria dos entrevistados também é do sexo masculino (64\%). Já na pesquisa de Zouain, Oliveira e Barone (2007), em consonância com os resultados apresentados por Motta e Trevissan (2003), verificou-se que entrevistados do sexo masculino formam a maior parcela de empreendedores jovens (80\%), com destaque para os resultados verificados, nesta mesma pesquisa, com os respondentes que estão associados à CONAJE, onde o número aumenta para 90,2\% de respondentes do sexo masculino.

Quando o assunto é a idade do jovem empreendedor, Borges, Filion e Simard (2008) mostraram que apenas $22 \%$ dos empreendedores possuíam idade entre de 18 a 24 anos, enquanto que $78 \%$ entre 25 e 34 anos. 0 estudo de Soares e Machado (2005) apresentou semelhança com o anterior, com uma frequência de 33,3\% dos respondentes com idade entre 18 a 24 anos, e $66,7 \%$ entre 25 e 34 anos.

Quanto ao estado civil, Soares e Machado (2005) verificaram 75\% do grupo são pessoas solteiras, o que segundo eles, difere do perfil geral empreendedor, que predomina o estado civil casado. Ribeiro e Teixeira (2012) encontraram uma maioria de solteiros.

No tocante a renda familiar observou-se no estudo de Zouain, Oliveira e Barone (2007) que quase $60 \%$ dos associados está acima de $\mathrm{R} \$ 7$ mil, enquanto que entre os não associados este número cai para $43,75 \%$, ambas consideradas alta para os padrões brasileiros. Ribeiro e Teixeira (2012) também apontou em seu estudo renda familiar relativamente alta. Entretanto, Bulgacov et al. (2011), dizem que de 36\% a 60\% dos empreendedores possuem renda de até 
3 salários mínimos, resultado divergente do apresentado acima.

No que tange motivações para a abertura de seus negócios, Borges, Filion e Simard (2008), em estudo realizado com 89 jovens canadenses, constataram que a principal razão indicada pelos jovens empreendedores é tirar proveito de uma oportunidade de negócio, além da oportunidade de ter uma empresa familiar, realizar um desafio, realizar um objetivo pessoal, e ainda fazer o que se gosta. Resultado semelhante ao encontrado por Ribeiro e Teixeira (2012), que constataram que os empreendedores entrevistados por elas iniciaram seus negócios baseados em motivações diversas, mas em todos se observa a percepção da oportunidade de negócio, da busca pela independência financeira e realização pessoal, o que fez alguns deles deixarem seus antigos empregos.

Em análise de um estudo realizado pelo GEM, que foi publicado em 2009, Bulgacov et al. (2011) observaram que os empreendedores jovens que empreendem por necessidade correspondem a $28 \%$ do total de empreendedores brasileiros, enquanto que os empreendedores jovens por oportunidade, correspondem a $29 \%$ do total dos empreendedores nacional.

Bulgacov et al. (2011) em pesquisa cujo tema foi Jovem empreendedor no Brasil: a busca do espaço da realização ou a fuga da exclusão?, levantaram informações sobre a formação escolar do jovem empreendedor brasileiro de 18 a 24 anos, no período de 2002 a 2008, concluíram que $61 \%$ dos dos entrevistados possuíam de cinco a 11 anos de escolaridade. Com uma frequência também significativa, demonstraram que, dentre estes jovens pesquisados, 21\% possuíam até quatro anos de escolaridade e somente $17 \%$ possuíam mais de 11 anos de escolaridade.

Diferente do que Bulgacov et al (2011) encontrou, Soares e Machado (2005) apontaram o que o empreendedor jovem possui elevado nível educacional, e que este fator, somado à formação em áreas gerenciais e a inserção em uma network, caracterizam indicadores de destaque que explicam o nível de sucesso deles. De acordo com Soares e Machado (2005), 58\% dos entrevistados possuíam pós-graduação, $17 \%$ ensino superior completo e $25 \%$ superior incompleto. Ao levantarem informações sobre a área de concentração dos estudos destes jovens respondentes, Soares e Machado (2005) apontaram as áreas de Turismo, Administração, Economia, Psicologia e Ciências Contábeis, refletindo significativo preparo em áreas gerenciais.

Já Lima Filho, Sproesser e Martins (2009) destacaram que todos (100\%) os participantes de sua pesquisa tinham ensino superior completo. Ribeiro e Teixeira (2012) também ressaltaram a eleva formação educacional de seus entrevistados, todos graduados. Zouain, Oliveira e Barone (2007), com seu estudo, também mostrou que os jovens empreendedores associados ou não a CONAJE possuem elevado grau de instrução formal, 83,2\% dos associados possuem superior completo ou alguma pós-graduação, enquanto os nãos associados (31,2\%) possuem superior completo e os demais, segundo grau completo $(68,8 \%)$.

Referente ao tempo de vida das empresas destes jovens, Soares e Machado (2005) destacaram que a maior parte das empresas $(54,5 \%)$ tem mais do que 5 anos; enquanto que $(36,5 \%)$ possuem entre dois e quatro anos e a penas (9\%) das empresas dos entrevistados foram iniciadas há menos de dois anos. As empresas do empreendedores pesquisados por Ribeiro e Teixeira (2012) são consideradas novas, tendo até 3 anos e meio de fundação.

No tocante a mobilização de recursos financeiros para a criação da empresa, os jovens 
geralmente começam com menos recursos que os outros empreendedores. Em estudo com 16 jovens empreendedores de Maringá, Soares e Machado (2005) constataram que o capital inicial dos jovens empreendedores é menor do que o dos empreendedores acima de 35 anos, o que não impediu à sobrevivência do negócio, pelo contrário, uma vez que eles demonstraram pretender ampliar os seus negócios e lançar novos produtos, além de desejarem abrir novas empresas, comportamento este que acabou por revelar o caráter proativo desses jovens entrevistados.

Ainda sobre a mobilização de recursos financeiros para a criação de empresas, Borges, Filion e Simard (2008), concluíram que, devido a pouca idade, os jovens entrevistados ainda não tinham acumulado o capital necessário para criar uma empresa, nem bens a oferecer como garantia para conseguir um empréstimo, valendo-se da ajuda financeira de familiares e amigos. A pesquisa realizada por Soares e Machado (2005) revelou que $63 \%$ dos jovens empreendedores abriram suas empresas com economias pessoais e apenas $9 \%$ utilizaram recursos familiares ou financiamento.

Em relação ao capital inicial investido, Soares e Machado (2005) verificaram em seu estudo que $25 \%$ das empresas iniciaram com capital igual ou inferior a $R \$ 5.000,00 ; 16,7 \%$ com capital entre $R \$ 5.000,00$ e $R \$ 10.000,00 ; 33,3 \%$ com capital entre $R \$ 10.001,00$ e $R \$$ $20.000,00$; e $25 \%$ com capital superior a $\mathrm{R} \$ 25.000,00$.

Sobre o setor da economia ao quais as empresas destes jovens empreendedores pertencem, Borges, Filion e Simard (2008) revelaram que 47\% dos jovens entrevistados criam suas empresas no setor de serviços; enquanto 38\% criam no setor secundário. Já a pesquisa realizada por Lima Filho, Sproesser e Martins (2009) obteve resultados semelhantes, sendo que 50\% empreendedores do setor comercial, $40 \%$ do setor de serviços e $10 \%$ do setor industrial. Ribeiro e Teixeira (2012) mostraram que o setor de serviços é predominante para a atuação dos empreendedores sergipanos pesquisados por elas.

Sobre a constituição societária das empresas, o resultado obtido por Borges, Filion e Simard (2008) revelou que em $74 \%$ dos casos pesquisados os jovens haviam criado a empresa em equipe, exercendo um papel polivalente quanto às responsabilidades iniciais, sendo esta a principal razão mencionada pelos entrevistados que os leva a escolher os outros sócios. Soares e Machado (2005) concluíram, em seus estudos, que uma minoria das empresas é constituída de firmas individuais (25\%). De acordo com estes estudiosos, em $75 \%$ dos casos pesquisados, as empresas foram constituídas por sócios, dos quais 66,7\% dos não são familiares. Ribeiro e Teixeira (2012) também apontaram que os empreendedores criam seus negócios com sócios.

De acordo com Borges, Filion e Simard (2008), o resultado sobre as funções que os jovens exercem nas novas empresas ganha ainda mais relevância quando confrontado com as informações sobre as experiências e as formações que os empreendedores tinham antes de criar a nova empresa. A experiência que os jovens entre 25 e 34 anos tinham em um cargo de direção antes de abrir a empresa não se demonstrou expressiva (média de 4 anos de experiência). Entre os jovens entrevistados com idade entre 18 a 24 anos, a média de experiência foi de zero ano. Isso significa que menos 50\% dos jovens de 18 a 24 anos criam sua empresa sem ter nenhuma experiência anterior em um cargo de direção.

Quanto ao número de empregados, observou-se nas pesquisas sobre este tema, que as empresas criadas por jovens são menores que de outros empreendedores em termo de 
número de empregados e de faturamento anual. Os resultados da pesquisa de Borges, Filion e Simard (2008) apontaram que elas tinham, em média, doze empregados, enquanto que as empresas criadas pelos empreendedores de 35 anos ou mais tinham dezessete. Soares e Machado (2005) mostraram, neste critério, que as empresas enquadram-se, na maioria (58\%), tinham até 10 funcionários; sendo que 41,6\% tem até 5 funcionários e 25\% como pequenas empresas, de 11 a 20 funcionários. Já as de médio porte foram representadas por 8,5\% com 21 a 50 funcionários, e o mesmo percentual, 8,5\%, para as com mais de 50 funcionários. Zouain, Oliveira e Barone (2007) verificaram que 17,1\% das empresas do grupo dos associados a CONAJE possuem apenas um empregado além do proprietário, 12,2\% possuem dois empregados e outros 12,2\%, quatro empregados, no outro grupo, a frequência de empresas que possuem apenas um empregado além do proprietário alcança 43,7\%.

No que tange ao faturamento anual as empresas criadas pelos jovens de 18 a 24 anos, $67 \%$ tiveram um faturamento de 500 mil dólares canadenses ou menos - contra $51 \%$ das empresas criadas pelos empreendedores de 25 a 34 anos e 48\% daquelas criadas pelos empreendedores de 35 anos ou mais (BORGES, FILION E SIMARD, 2008). Pesquisas realizadas na França também mostram que o faturamento das empresas criadas pelos jovens de menos de 30 anos é menor do que o das empresas criadas pelos empreendedores mais velhos (APCE, 2001).

Além dos indicadores que revelam o perfil destes jovens empreendedores, algumas os pesquisadores, a exemplo de Borges, Filion e Simard (2008), aferiram que o fato de as empresas criadas pelos jovens serem menores em termos de número de empregados e de faturamento é justificada pelo fato dos jovens iniciarem suas respectivas empresas com menos recursos financeiros do que os outros empreendedores. Outra justificativa apresentada pelos estudiosos anteriormente mencionados é o fato de estes jovens criarem mais empresas no setor no ramo de serviços do que os outros empreendedores e, nesse setor, o faturamento inicial é geralmente menor do que no setor secundário.

Em síntese, os resultados apresentados nas pesquisas citadas nos revelam que os jovens empreendedores no Brasil são do sexo masculino, solteiros, possuem elevado nível educacional, com empresas no setor de serviço e de pequeno porte, e que iniciam suas atividades em sociedade. Observou-se também que poucos são os jovens que são associados órgãos que incentivem o empreendedorismo jovem.

\section{Procedimentos metodológicos}

A presente pesquisa caracteriza-se por ser de natureza quantitativa, predominantemente descritiva. Gil (1999) revela que a pesquisa descritiva expõe características de determinada população ou fenômeno, podendo até estabelecer correlações entre as variáveis, definindo sua assim sua natureza. Em relação ao momento de coleta de dados, esta se classifica como de corte transversal, pois a coleta de dados ocorreu em um só momento, pretendendo descrever e analisar o estado de uma ou mais variáveis em um dado momento (FREITAS et al. 2000).

A estratégia principal de pesquisa adotada neste estudo é a pesquisa survey. Segundo Freitas et al. (2000) as principais características deste método de pesquisa são: o interesse em produzir descrições quantitativas de uma população, por meio de representantes da mesma, chamados de amostra, e o uso de um instrumento predefinido, normalmente um questionário.

Para a obtenção da explicação do fenômeno aqui pesquisado foi utilizado um questionário sócio demográfico, aplicado entre os meses de março e abril de 2012. O mesmo foi 
disponibilizado online, através da plataforma Goole Docs, um recurso do Google para criação de formulários e outros tipos de arquivos. Os questionário foram enviados via facebook, email e também entregue impresso. A confiabilidade e anonimato do participante e das empresas é garantida, apenas informações necessárias ao propósito da pesquisa foram utilizadas.

A população de pesquisa selecionada foi os jovens empreendedores, aqueles com idade entre 18 e 34 anos, da cidade de Aracaju, Sergipe. Faz-se ainda necessário seus negócios terem sido fundados entre os anos de 2005 a 2011, e que possua pelo menos 1 (um) subordinado. Os respondentes foram obtidos através de indicações, inclusive foi criada uma campanha via facebook, com o intuito de encontrar possíveis respondentes. Também foi criado um grupo na mesma rede social, com intuito de sanar dúvidas em relação a pesquisa e ainda conseguir indicações de possíveis respondentes.

De acordo com a classificação de Freitas et al. (2000), a amostra desta pesquisa é do tipo não probabilística, onde os critérios de escolha se deu por conveniência e bola de neve. Esta pesquisa obteve 35 respondentes para o questionário, destes 8 foram descartados, restando 27 questionários válidos, no entanto foram enviados 53 questionários para possíveis respondentes. No quadro 01 a seguir são apresentadas as dimensões, variáveis e indicadores utilizados no estudo.

\section{Quadro 01 - Dimensões, Variáveis e Indicadores}

\begin{tabular}{|c|c|c|}
\hline & VARIÁVEIS & INDICADORES \\
\hline \multirow[t]{2}{*}{ 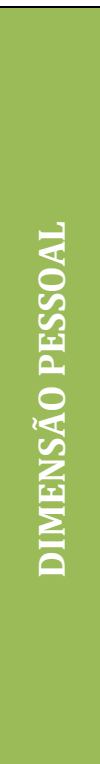 } & $\begin{array}{c}\text { Perfil dos } \\
\text { Empreendedores }\end{array}$ & $\begin{array}{l}\text { - } \text { Participação no CJE } \\
\text { - Sexo } \\
\text { - Idade } \\
\text { - Escolaridade } \\
\text { - Estado Civil } \\
\text { - Renda Familiar } \\
\text { - Experiência de Liderança }\end{array}$ \\
\hline & $\begin{array}{c}\text { Motivação para } \\
\text { Empreender }\end{array}$ & $\begin{array}{l}\text { - Oportunidade: realização pessoal; independência financeira; } \\
\text { oportunidade do mercado; ou aumento da renda. } \\
\text { - Necessidade: desemprego; ou sustento da família. }\end{array}$ \\
\hline 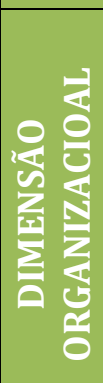 & $\begin{array}{l}\text { Caracterização } \\
\text { da Empresa }\end{array}$ & $\begin{array}{l}\text { - } \text { Tempo de Fundação } \\
\text { - } \text { Setor da Economia } \\
\text { - } \quad \text { Número de Funcionários } \\
\text { - } \quad \text { Capital Inicial } \\
\text { - } \text { Origem dos Recursos }\end{array}$ \\
\hline
\end{tabular}


Fonte - Autores com base na revisão da literatura (2012)

Após a coleta, foi feito a tabulação análise e interpretação dos dados. A análise tem como objetivo organizar e codificar os dados de maneira que possibilitem a geração de respostas no problema proposto de investigação. A interpretação tem como finalidade a procura do sentido mais amplo das respostas, o qual é realizado comparando os resultados com os conhecimentos absorvidos (GIL, 1999). Foram feitas análises de frequências (relativas e absolutas) através do SPSS.

\section{Perfil dos empreendedores jovens de Aracaju}

Com o intuito de caracterizar o perfil dos empreendedores jovens de Aracaju, foram usadas as seguintes variáveis: participação no CJE, sexo, idade, escolaridade, estado civil, renda familiar, e experiência de liderança. Os dados sobre o perfil dos entrevistados foram apresentados de forma agrupada, conforme demonstrado na tabela 01, para que os resultados pudessem ser facilmente visualizados e compreendidos.

Tabela 01 - Distribuição percentual dos jovens empreendedores de Aracaju conforme variáveis do estudo

\begin{tabular}{|c|c|c|c|}
\hline PERFIL DOS EMPREENDEDORES & $\begin{array}{c}\text { Frequência } \\
\text { absoluta }\end{array}$ & $\begin{array}{l}\text { Frequência } \\
\text { relativa \% }\end{array}$ & TOTAL (\%) \\
\hline \multicolumn{4}{|l|}{ Participação no CJE } \\
\hline Não & 22 & 81,5 & 81,5 \\
\hline Sim & 5 & 18,5 & 100,0 \\
\hline \multicolumn{4}{|l|}{ Sexo } \\
\hline Feminino & 7 & 25,9 & 25,9 \\
\hline Masculino & 20 & 74,1 & 100,0 \\
\hline \multicolumn{4}{|l|}{ Idade } \\
\hline 18 a 24 & 8 & 29,6 & 29,6 \\
\hline 25 a 34 & 19 & 70,4 & 100,0 \\
\hline \multicolumn{4}{|l|}{ Estado Civil } \\
\hline Casado & 8 & 29,6 & 29,6 \\
\hline Separado & 1 & 3,7 & 33,3 \\
\hline Solteiro & 18 & 66,7 & 100,0 \\
\hline \multicolumn{4}{|l|}{ Escolaridade } \\
\hline $\begin{array}{l}\text { Ens. Superior Completo ou } \\
\text { Incompleto }\end{array}$ & 17 & 63,0 & 63,0 \\
\hline Pós-Graduação ou Superior & 10 & 37,0 & 100,0 \\
\hline
\end{tabular}




\begin{tabular}{lccc}
\hline Renda Familiar & 1 & 3,7 & \\
Até 3 Salários & 3 & 11,1 & 14,7 \\
\hline De 3 a 6 Salários & 7 & 25,9 & 40,7 \\
\hline De 6 a 9 Salários & 16 & 59,3 & 100,0 \\
\hline Mais de 9 Salários & & & \\
\hline Experiência de Liderança & 10 & 37,0 & 37,0 \\
Nenhuma & 4 & 14,8 & 51,8 \\
\hline Até 2 anos & 13 & 48,2 & 100,0 \\
\hline Mais de 2 anos & & & \\
\hline \hline
\end{tabular}

Fonte: Pesquisa de Campo (2012)

Ao analisar os dados apresentados na tabela 01, é possível observar que, dentre os 27 (100\%) respondentes, apenas $5(18,5 \%)$ deles participam ou participaram do CJE, enquanto que $81,5 \%(n=22)$ afirmaram nunca ter participado. Pode-se dizer que os jovens entrevistados ainda não compreendem, ou não conhecem a importância destas associações e as suas implicações no desenvolvimento de competências dos empreendedores, bem como as facilitações no processo de negociação e conhecimento do mercado, essenciais para o sucesso de toda e qualquer empresa. Além disso, pressupõe-se que a divulgação do CJE talvez não esteja alcançando o seu público ou suas ações locais não estejam motivando a participação dos empreendedores jovens.

O estudo de Zouain, Oliveira e Barone (2007), feito com associados e não associado da CONAJE poderia trazer resultados para esta comparação. A pesquisa dos autores contemplaria jovens empreendedores com idade entre 18 e 34 anos e foi dimensionada para ser respondida por 1.500 associados e 330 não associados, ou seja, 81,97\% para associados e 18,03\% para não associados. Porém, no estudo não há informações se esta proporção foi confirmada ou não, através dos resultados. Portanto, se for considerado apenas a proporção estimada inicialmente, haveria semelhança entre os estudos.

Com relação ao sexo dos entrevistados, a grande maioria $(n=20)$ dos entrevistados $(74 \%)$ pertence sexo masculino, sendo apenas $26 \%(n=7)$ do pertencente ao sexo feminino. Este resultado confirma o modelo tradicional das famílias, principalmente as pertencentes à classe média, onde há uma divisão clara de papéis, em que o homem busca o trabalho remunerado ou a sua independência financeira empreendendo e a mulher, ou cuida dos afazeres domésticos ou, como acontece nos dias atuais, vai à busca de um ofício que lhe permite conciliar a vida pessoa e profissional com qualidade de vida, mesmo que a sua remuneração seja menor do que a do homem, responsável este pelo provimento das necessidades familiares.

0 resultado apresentado converge com os apresentados nas pesquisas de Soares e Machado (2005); Zouain, Oliveira e Barone (2007); Ribeiro e Teixeira (2012); e Motta e Trevissan (2003), onde a grande maioria dos respondentes pertence ao sexo masculino. No entanto, os resultados divergem dos apresentados no estudo de Lima Filho, Sproesser e Martins (2009) onde houve a igualdade entre os sexos dos respondentes. Resultado semelhante ao da 
pesquisa GEM (2011), no contexto geral sobre empreendedorismo brasileiro, 10,7 milhões pertence ao sexo masculino, 50,7\%, e 10,4 milhões ao feminino, 49,3\%.

Ao analisar a categoria idade, deve-se ressaltar, inicialmente que, para a presente pesquisa que se propôs a estudar o estilo de liderança dos empreendedores jovens de Aracaju, a idade mínima para que pudesse responder ao questionário foi de 18 anos e a máxima era de 34 anos, obedecendo ao modelo utilizado pelo GEM.

Pode-se notar uma maior incidência de respondentes na faixa etária de 25 a 34 anos, com pouco mais de 70\% dos respondentes. Deve-se ressaltar que esta idade demonstra um maior amadurecimento destes jovens, principalmente por parte daqueles que acabam de concluir uma graduação ou curso tecnológico e que busca aplicar, na prática, todo o conhecimento acumulado durante o seu desenvolvimento profissional. Trata-se do período da "busca de significado" destes jovens pela sua formação.

Verifica-se que houve semelhança nos resultados à literatura pesquisada, comparando com os dos estudos de Soares e Machado (2005) e de Borges, Filion e Simard (2008) que mostraram, pelo menos, mais de dois terços dos empreendedores jovens com idade entre 25 e 34 anos. Semelhante também ao resultado do GEM (2012), que apresentou um total de 32,45\% empreendedores com esta idade, o que, se agregado aos outros jovens de menor idade (18 a 24 anos, $19,45 \%=51,99 \%$ ) representa proporcionalmente $62,41 \%$.

Outro aspecto analisado no estudo foi o estado civil. Dentre os entrevistados, há uma frequência significativa (66,7\%) de jovens solteiros. Possivelmente pela idade dos respondes, talvez pela dedicação ao negócio, ou ainda estão aguardando a estabilização financeira e gerencial do negócio para firmarem matrimônio. Soma-se a isso o fato destes jovens, pertencentes à geração $\mathrm{Y}$, desejarem conforto, estabilidade, não alimentando o desejo pelo casamento sem que todos os requisitos de conforto que eles têm nas casas de seus pais sejam supridos. Tais dados obtidos são convergentes e reforçados no estudo de Soares e Machado (2005) que também obteve índices elevados de jovens solteiros, representado por $75 \%$ do grupo pesquisado. E também com os resultados de Ribeiro e Teixeira (2012).

Com relação ao nível de escolaridade dos jovens empreendedores da Grande Aracaju, é possível averiguar que $63 \%$ dos respondentes concluíram ou estão cursando o ensino superior, enquanto que $37 \%$ é pós-graduado (especialista, mestre ou doutor). Tais dados nos permitem aferir o alto grau de qualificação dos jovens empreendedores, o que pode apontar para um perfil diferenciado de profissional, obstinado em seus objetivos e conscientes de suas ações.

Os resultados encontrados foram de encontro aos achados de Zouain, Oliveira e Barone (2007), nos quais pelo menos $31,2 \%$ dos empreendedores jovens possuem ensino superior completo. Contudo o resultado foi ao encontro da pesquisa realizada por Soares e Machado (2005), Lima Filho Sproesser e Martins (2009) e Ribeiro e Terixeira (2012), que também apontou para uma maioria de entrevistados graduada ou estão concluindo o nível superior, além de apresentar resultados significativos de empreendedores com pós-graduação.

No que tange à média da renda familiar, nota-se que os níveis de rendimento são relativamente altos, visto que 59,3\% dos jovens empreendedores de Aracaju possuem renda familiar superior a 9 salários mínimos, enquanto que apenas 3,7\% apontou possuir renda de até 3 salários. Zouain, Oliveira e Barone (2007) observaram 43\% dos jovens empreendedores pesquisados em sua pesquisa, possui renda acima de $\mathrm{R} \$ 7$ mil, o que é considerada alta para 
os padrões brasileiros, convergindo para os resultados obtidos na presente pesquisa. Em contrapartida ao resultado obtido, Bulgacov et al. (2011), diz que de $36 \%$ a $60 \%$ dos empreendedores possuem renda de até 3 salários mínimos, não refletindo os resultados obtidos. Ribeiro e Teixeira (2012), também apontaram para uma renda relativamente alta.

Outra categoria que merece destaque tem relação à experiência com liderança dos jovens empreendedores pesquisados. Ao observar a tabela 01 é possível verificar que a grande maioria dos entrevistados possui experiência de liderança, $63,0 \%$, sendo que destes $48,2 \%$ possuem mais de 2 anos de experiência.

O estudo de Borges, Filion e Simard (2008) apontou que apenas os jovens com idade mais elevada, 25 a 34 anos, apresentavam experiência em cargo de direção, possuindo uma média de 4 anos. Diferente do encontrado, onde foram encontrados empreendedores mais novos, 18 a 24 anos, com experiência de gestão. Contudo o resultado apresentado mostra que a maioria dos empreendedores jovens com idade acima de 24 anos já teve algum tipo de experiência de liderança, o que pode ter facilitado sua inserção no mercado.

Pode-se afirmar que, com base no discutido, a maioria dos resultados alcançados está convergente aos encontrados na literatura. Observa-se que os empreendedores jovens de Aracaju, em grande parte, não são associados ao CJE, ou órgão semelhante. A sua maioria é do sexo masculino, na faixa etária mais elevada, possui grau de educação formal e renda familiar elevada, solteiros e com certa de experiência com liderança.

\section{Motivação dos empreendedores}

Buscou-se nessa etapa da pesquisa conhecer as motivações que levaram os jovens empreendedores de Aracaju a criarem seus negócios. É possível observar a Tabela 02, que quase a totalidade, (96,3\%) dos empreendedores afirmou que o principal motivo para empreender foi por oportunidade, enquanto que apenas 3,7\% disseram ter sido por necessidade. É observado ainda que a maioria dos respondentes citou a "realização profissional", 37,0\%, como o principal motivo para a abertura do seu próprio negócio. Também apresentam frequências significativas, a oportunidade identificada no mercado, $29,6 \%$, e a independência financeira, $25,9 \%$.

Tabela 02 - Distribuição percentual dos entrevistados por motivos que os levaram a abrir o seu próprio negócio

\begin{tabular}{lccc}
\hline \hline \multicolumn{1}{c}{$\begin{array}{c}\text { MOTIVAÇÃO PARA } \\
\text { EMPREENDER }\end{array}$} & $\begin{array}{c}\text { Frequencia } \\
\text { absoluta }\end{array}$ & $\begin{array}{c}\text { Frequencia } \\
\text { relativa \% }\end{array}$ & TOTAL (\%) \\
\hline \hline Motivação & 10 & 37,0 & 37,0 \\
\hline Realização Pessoal & 8 & 29,6 & 66,6 \\
\hline Oportunidade de Mercado & 7 & 25,9 & 92,5 \\
\hline Independência Financeira & 1 & 3,7 & 96,2 \\
\hline Sustento da Família & 1 & 3,7 & 100,0 \\
\hline Aumento da Renda & & & \\
\hline Motivação Compilada & & &
\end{tabular}


Felipe Carvalhal, Ana Luísa Leão e Rivanda Meira Teixeira

\begin{tabular}{lccc} 
Oportunidade & 26 & 96,3 & 96,3 \\
Necessidade & 1 & 3,7 & 100,0 \\
\hline \hline
\end{tabular}

Fonte: Pesquisa de Campo (2012)

Motta e Trevisan (2003) apontaram como motivação dos empreendedores antes de iniciar o negócio a busca de realização pessoal. Já Borges, Filion e Simard (2008) constataram que a principal razão indicada pelos jovens é tirar proveito de uma oportunidade de negócio. E Ribeiro e Teixeira (2012) perceberam a oportunidade de mercado, mas a realização pessoal também foi relatada. Com base nestes resultados pode-se perceber que há uma congruência entre os resultados dos ressaltados na literatura e o encontrado na pesquisa.

Como visto, os resultados encontrados convergem aos apresentados na literatura pesquisa, onde o jovem empreendedor cria seu negócio por oportunidade, procurando a realização pessoal, aproveitando uma oportunidade de mercado ou ainda buscando sua independência financeira. Isto pode ser explicado pelo fato que jovens ainda não possuem tantas responsabilidades e podem se arriscar mais em seus sonhos e aproveitarem as oportunidades que surgirem.

\section{Caracterização das empresas criadas pelos jovens}

Nesta etapa da pesquisa, buscou-se conhecer as características das empresas dos jovens empreendedores de Aracaju. A tabela 03 traz informações a respeito dessas empresas, como o ano de fundação, setor da economia, sócios, recurso para abrir o negócio e o montante do capital para iniciar o negócio.

Tabela 03 - Distribuição percentual dos entrevistados de acordo com as características de suas empresas

\begin{tabular}{lccc}
\hline \hline CARACTERIZAÇÃO DAS EMPRESAS & n & $\%$ & TOTAL (\%) \\
\hline Ano de Fundação & 2 & 7,4 & 7,4 \\
2005 & 3 & 11,1 & 18,5 \\
\hline 2007 & 4 & 14,8 & 33,3 \\
\hline 2008 & 4 & 14,8 & 48,1 \\
\hline 2009 & 7 & 25,9 & 74,1 \\
\hline 2010 & 7 & 25,9 & 100,0 \\
\hline 2011 & & & 22,8 \\
\hline Setor da Economia & 6 & 22,2 & 100,0 \\
\hline Comércio & 21 & 77,8 & \\
\hline Serviço & & & \\
\hline Número de Empregados & & & \\
\hline
\end{tabular}




\begin{tabular}{|c|c|c|c|}
\hline 1 a 3 & 11 & 40,7 & 40,7 \\
\hline De 4 a 6 & 7 & 25,9 & 66,6 \\
\hline De 7 a 25 & 7 & 25,9 & 92,5 \\
\hline Mais que 25 & 2 & 7,4 & 100,0 \\
\hline \multicolumn{4}{|l|}{ Possui Sócio } \\
\hline Não & 7 & 25,9 & 25,9 \\
\hline Sim & 20 & 74,1 & 100,0 \\
\hline \multicolumn{4}{|l|}{$\begin{array}{l}\text { Número de Sócios (dos que } \\
\text { possuem) }\end{array}$} \\
\hline 1 & 12 & 60,0 & 60,0 \\
\hline 2 & 6 & 30,0 & 90,0 \\
\hline 3 & 2 & 10,0 & 100,0 \\
\hline \multicolumn{4}{|l|}{ Capital Inicial } \\
\hline Até R\$ 2000 & 3 & 11,1 & 11,1 \\
\hline De $\mathrm{R} \$ 2.000$ até $\mathrm{R} \$ 5.0000$ & 5 & 18,5 & 29,6 \\
\hline De $\mathrm{R} \$ 5.000$ até $\mathrm{R} \$ 10.0000$ & 3 & 11,1 & 40,7 \\
\hline De $\mathrm{R} \$ 10.000$ até $\mathrm{R} \$ 20.0000$ & 1 & 3,7 & 44,4 \\
\hline De $\mathrm{R} \$ 20.000$ até $\mathrm{R} \$ 50.0000$ & 4 & 14,8 & 59,2 \\
\hline De $\mathrm{R} \$ 50.000$ até $\mathrm{R} \$ 100.0000$ & 6 & 22,2 & 81,4 \\
\hline Mais de $\mathrm{R} \$ 100.000$ & 5 & 18,5 & 100,0 \\
\hline \multicolumn{4}{|l|}{ Origem dos Recursos } \\
\hline Família & 1 & 3,7 & 3,7 \\
\hline Próprios & 11 & 40,7 & 44,4 \\
\hline Próprios + Família & 5 & 18,5 & 63,0 \\
\hline Próprios + Sócio & 10 & 37,0 & 100,0 \\
\hline
\end{tabular}

Fonte: Pesquisa de Campo (2012)

Com relação ao ano de fundação dos seus respectivos negócios, observa-se que a maioria (50\%) dos empreendimentos foi criada entre os anos de 2011 e 2012. Isso significa dizer que mais das metades dos entrevistados possuem menos de dois anos de empresa. Também em 2008 e 2009 é possível observar uma frequência significativa $(29,6 \%)$ de empresas criadas neste período. Com uma frequência mais tímida $(18,5 \%)$, encontram-se as empresas fundadas antes de 2007. 
0 resultado apresentado difere do encontrado por Soares e Machado (2005), quando constataram que $54,5 \%$ das empresas têm mais de 5 anos de fundação. No entanto, foi convergente ao encontrado por Ribeiro e Teixeira (2012), no qual apontou que as empresas tinham menos de 3 anos e meio.

Quanto ao setor da economia no qual as empresas atuam, a grande maioria (77,8\%) caracteriza-se como prestadoras de serviços. Este dado pode estar relacionado ao fato de ser mais fácil abrir um negócio neste setor do que em outros. 0 mesmo resultado pode ser verificado nos estudos de Borges, Filion e Simard (2008), Soares e Machado (2005), Zouain, Oliveira e Barone (2007) e Ribeiro e Teixeira (2012), quando foram demonstradas que a maioria das empresas criadas pelos jovens empreendedores foi no setor de serviços, embora com variações significativas de frequência de citações. Já Lima Filho, Sproesser e Martins (2009) obtiveram resultados divergentes, ao concluir que 50\% das empresas criadas pelos jovens empreendedores foram no setor comercial.

No que tange ao número de empregados, observa-se cerca de $40 \%$ dos empreendedores possuem de 1 a 3 empregados em suas empresas, enquanto que apenas 7,4\% possuem mais de 25 , sendo que mais da metade das empresas contam com um quadro funcional de 4 a 25 funcionários.

Borges, Filion e Simard (2008), em seu trabalho, apontaram que, em média, as empresas criadas por jovens empreendedores tinham 12 empregados. Soares e Machado (2005) verificaram que $41,6 \%$ das empresas dos jovens possuem até 5 funcionários, enquanto que 25 contam 11 a 20 funcionários, 8,5\% 21 a 50 funcionários e mesmo percentual para empresas com mais de 50 funcionários. Observa-se que os resultados obtidos vão ao encontro da literatura, visto que os jovens empreendedores, em sua maioria, possuem empresas com poucos funcionários, caracterizadas como pequenas ou microempresas.

Questionados sobre a formação de sociedade nos negócios, observa-se a cautela por parte dos empreendedores, pois em grande parte eles não se arriscarem sozinhos; e, ao mesmo tempo, o acreditar no negócio que se pretendeu abrir, na medida em que 74,1\% dos respondentes informaram ter sócios nos seus respectivos empreendimentos. Destes 60,0\% possuem um sócio, 30,0\% dois sócios e 10,0\% três sócios.

Os índices encontrados nesta pesquisa foram convergentes aos encontrados por Soares e Machado (2005), 75\%; e por Borges, Filion e Simard (2008), que obtiveram 74\% de empresas criadas em conjunto. Uma razão que pode levá-los a escolher os outros sócios é o complemento de suas competências e dos recursos disponíveis, sejam eles financeiro ou não, para abrir a empresa.

Sobre o montante do capital utilizado para a abertura do próprio negócio notou-se que $40,7 \%$ utilizam até $R \$ 10.000,00$, a mesma frequência o fazem com mais de $R \$ 50.000,00$, enquanto o restante $(18,5 \%)$ aplicaram de $\mathrm{R} \$ 10.000,00$ até $\mathrm{R} \$ 50.000,00$ em seus negócios. Pode-se aferir que os resultados encontrados nesta pesquisa se assemelham aos encontrados por Soares e Machado (2007), principalmente no que tange a aquelas que utilizaram até R\$ $10.000,00(41,7 \%)$. É visto que grande parte utilizam poucos recursos financeiros, o que pode ser entendido devido a pouca idade dos empreendedores, o que não possibilitou o acúmulo de capital necessário para maiores investimentos.

Quanto à origem do recurso utilizado para a abertura do negócio, 40,7\% mencionou que os recursos foram próprios. Em 55,5\% dos casos eles iniciam seus negócios com o apoio 
financeiro de alguém, seja do sócio (37,0\%) ou da família (18,5\%). Apenas um empreendedor informou ter contado apenas com o recursos familiares para a abertura do seu negócio, 3,7\%.

Os resultados do estudo da pesquisa de Borges, Filion e Simard (2008) salientou que os jovens valem-se do chamado capital de proximidade, love money, que nada mais é do que a ajuda financeira de familiares e amigos, semelhante ao resultado encontrado. Contudo, Soares e Machado (2005) verificaram que 63\% deles abriram suas empresas com economias pessoais e a minoria com o apoio de outra pessoa, resultado divergente do encontrado nesta pesquisa.

A seguir são apresentados os resultados sobre as características das empresas pesquisas.

Diante do exposto, pode-se verificar em todos os aspectos pesquisados estão em consonância com a literatura pesquisada, exceto no que se refere a idade das empresas relatadas, onde foi percebido que os empreendedores pesquisados possuem empresas recentemente criadas. É notório que as empresas deles são de pequeno porte, atuante no setor de serviço, e que para montarem o negócio o empreendedor jovem, busca fazê-lo em sociedade, investindo muitas vezes considerado capital inicial, que geralmente é de origem própria, ou com apoio da família ou sócio.

\section{Conclusões}

Diante do apresentado nesta pesquisa pode-se perceber o quanto é valoroso o empreendedorismo para o bem estar social e econômico, independente do tipo do negócio. Dentre os empreendedores foi ressaltado o papel dos mais jovens, aqueles com idade entre 18 e 34 anos, dada a valorização do jovem para o desenvolvimento de uma nação. A partir deste cenário de destaque procurou-se, a partir de análise criteriosa, estabelecer suposições a respeito do perfil, motivação para empreender e características das empresas dos jovens empreendedores da cidade de Aracaju-SE.

Conhecer o perfil destes jovens empreendedores se faz importante para que sejam traçadas políticas direcionadas para este público, procurando satisfazer as suas necessidades e contribuindo para o desenvolvimento dos negócios dos mesmos, ou até incentivando outros a enveredarem por este caminho.

No que tange ao perfil destes jovens foi observado que: 81,5\% não são participantes do CJE; grande parte $(74,1 \%)$ é do sexo masculino; com relação à idade verifica-se maior incidência está entre 25 e 34 anos de idade (70,4\%); a maioria dos entrevistados é solteiro (66,7\%); têm ensino superior incompleto ou completo (63\%); possuem renda acima de nove salários mínimos (59,3\%); e já tiveram experiência de liderança (59,3\%), e 29,7\% destes mais de dois anos.

Saber a motivação que leva uma pessoa a criar um negócio, a arriscar seu capital ou de terceiros em algo que lhe vai tomar grande parte do tempo do seu dia a dia faz-se necessário, pois são cada empreendedor possui uma razão particular para iniciar sua empresa. Quanto a isto se verificou que $96,3 \%$ dos empreendedores jovens pesquisados empreendem por oportunidade, sendo que a principal motivação foi realização pessoal $(37,0 \%)$, seguida de oportunidade de mercado $(29,6 \%)$ e independência financeira $(25,9 \%)$.

Ter ciência de quais são as características das empresas dos empreendedores pesquisados é útil no mesmo sentido de se conhecer o perfil dos mesmos, para orientar melhor as ações e políticas que podem desenvolvidas para eles e suas empresas. Com relação às mesmas, percebeu-se que a maioria das empresas foi fundada no ano de 2010 e 2011 (51,8\%), ambos 
com a mesma porcentagem (25,9\%); pertencem ao setor de serviços $(77,8 \%)$; boa parte possui de 1 a 3 funcionários em (40,7\%); foram criada em sociedade (74,1\%), destas 60,0\% possuem apenas um sócio; foi necessário o montante de até $\mathrm{R} \$ 10.000,00(40,7 \%)$ ou mais de $\mathrm{R} \$ 50,000,00$ (40,7\%) para iniciar o negócio; e foi utilizado recursos próprios na abertura $(40,7 \%)$, seguido pela junção de recursos próprios com os da sociedade feita $(37,0 \%)$.

Por fim vale ressaltar que o perfil do jovem empreendedor aracajuano muito se assemelha ao encontrado na literatura. Deve-se destacar que possui um nível de educação formal muito elevado, o que pode ter influenciado suas motivações para empreender. Além disso, esses jovens são oriundos de famílias de classe média ou alta, solteiros que não estão pronto a abdicar de todo o conforto das casas de seus pais, sem antes estarem estabilizados financeiramente. Argumenta-se ainda a relevância da pesquisa aqui relatada, em função da escassa literatura brasileira publicada sobre os jovens empreendedores que poderá servir de base comparação e referência para eventuais pesquisas que abordem o mesmo tema.

\section{Referências}

APCE (AGENCE POUR LA CRÉATION D'ENTREPRISES). Les jeunes et la création d'entreprise, 2001. Disponível em: <http://www.apce.com>. Acesso em: 10 jun. 2005.

ARMOND, A. C, NASSIF, V. M. J. A Liderança como elemento do comportamento empreendedor: um estudo exploratório. RAM - REVISTA DE ADMINISTRAÇÃO MACKENZIE, V. 10, N. 5. SÃO PAULO, SP, SET./OUT. 2009

BOAVA, D. L. T, MACEDO, F. M. F. ESTUDO SOBRE A ESSÊNCIA DO EMPREENDEDORISMO. In: Encontro da ANPAD, 30. 2006. Salvador, BA. Anais.. Salvador, 2006.

BORGES, C, FILION, L. J, SIMARD, G. Jovens Empreendedores e o Processo de Criação de Empresas. RAM - REVISTA DE ADMINISTRAÇÃO MACKENZIE, V. 9, N. 8, Edição Especial. NOV./DEZ. 2008

BULGACOV, Y. L. M.; CUNHA, S. K.; CAMARGO, D.; MEZA, M. L.; BULGACOV, S. Jovem empreendedor no Brasil: a busca do espaço da realização ou a fuga da exclusão?. Revista de Administração Pública - Rio de Janeiro V. 45, Maio/jun. 2011

DORNELAS, J. C. A. Empreendedorismo: transformando idéias em negócios. Rio de Janeiro: Campus. 2001

DUTRA, I. S, PREVIDELLI, J. J. Perfil do empreendedor versus mortalidade de empresas: Estudo de caso do perfil do micro e pequeno empreendedor. IN: ENANPAD, 2003, 27, Atibaia, SP. Anais... Atibaia, 2003.

ESTRELLA, J. Regarding microcredit as a policy to reduce inequalities and improve wellbeing. 2007. (Versão preliminar da tese de doutorado).

FREITAS, H, OLIVEIRA, M, SACCOL, A. Z, MOSCAROLA, J. O método de pesquisa. Revista de Administração. São Paulo, v. 35 - n. 3, p. 105-112/setembro 2000.

GIL, Antonio Carlos. Como elaborar projetos de pesquisa. São Paulo: Atlas, 1999.

GIMENEZ. F. A. P., INACIO JUNIOR, E. Investigando o potencial empreendedor e liderança criativa, In: ENCONTRO NACIONAL DA ASSOCIAÇÃO NACIONAL DOSCURSOS DE POS- 
GRADUAÇÃo EM ADMINISTRAÇÃO, 26., 2002, Salvador. Anais...Salvador, 2002.

GLOBAL ENTREPRENEURSHIP MONITOR, GEM. 2010. Disponível em:

<http://www.biblioteca.sebrae.com.br/bds/bds.nsf/1d7b269b07fee04a03256eae005ec615/ 5d1cac412448b0428325757b00697dc7/\$FILE/NT0003EF2A.pdf >. Acesso em: 16 set. 2011.

GLOBAL ENTREPRENEURSHIP MONITOR, GEM. 2011. Disponível em:

<http://www.ibqp.org.br/img/projetos/downloads/arquivo 20120705121115.pdf > . Acesso em: 05 de setembro de 2012.

HONMA, E. T, TEIXEIRA, R. M. COMPETÊNCIAS EMPREENDEDORAS EM HOTÉIS DE PEQUENO PORTE: ESTUDO DE MÚLTIPLOS CASOS EM CURITIBA, PARANÁ. Revista Turismo Visão e Ação - Eletrônica, Vol. 13 - no 1 - p. 52-80 / jan-abr 2011

LICHT, R. H. G., OLIVEIRA, P. S. G., VENTURA, V. L. S. Avaliação do Perfil de Empreendedores utilizando a Teoria de Tipos Psicológicos. RBGN, São Paulo, Vol. 9, n. 24, p. 31-40, maio/ago. 2007

LIMA FILHO, D. O.; SPROESSER, R. L.; MARTINS, E. L. C. Empreendedorismo e Jovens Empreendedores. Revista de Ciências da Administração, v. 11, n. 24, p. 246-277. Maio/ago 2009

LOPEZ JUNIOR, G, SOUZA, E. C. L. Atitude Empreendedora: Conceitos, Modelos e Medidas. In: Simpósio de Gestão da Inovação Tecnológica, 25. 2008. Brasília, DF, 22 a 24 de outubro de 2008.

MACHADO, H. P. V, GIMENEZ, F. NA P. Empreendedorismo e Diversidade: Uma Abordagem Demográfica de Casos Brasileiros. EGEPE, 1, 2000, Maringá,PR. Anais... Maringá, 2000.

MARTINELLI, L. A. S, FLEMING, E. S. O Comportamento Empreendedor: a Influência das Características Emocionais na Motivação dos Indivíduos para a Ação Empreendedora. In: Encontro da ANPAD, 34, 2010, Rio de Janeiro, RJ. Anais... Rio de Janeiro, 2010.

MINOLA, L. C. T.; CRIACO, G. Youth Entrepreneurship: Proposal of an assessment scheme for policy Initiatives. Disponível em

<http://www.icsb.org/assets/icsbgw criacocassia fullpaper.pdf $>$ Acesso em 20.05.2012

MORRISON, A. (Editor). Entrepreuneurship - An International Perspective. Oxford: Butterworth- Heinemann, 1998.

MOTTA, J. P, TREVISAN, M. Perfil de empreendedores: Associação de jovens empresários de Santa Maria/RS. SEMEAD, 7, 2003, São Paulo, SP. Anais... São Paulo, 2003.

RIBEIRO, T. M.; TEIXEIRA, R. M. A criação de negócios por empreendedores jovens: estudo de casos múltiplos no estado de Sergipe. Revista de Empreendedorismo e Gestão de

Pequenas Empresas - REGEPE, Brasil, v.1, n.1, jan/abril de 2012.

SCHOOF, U. Stimulating Youth Entrepreneurship: Barriers and Incentives to Enterprise StartUps by Young People. SEED Working Paper International Labour Office, 76. 2006

SOARES, M. A. F., MACHADO, H. P. V. Jovens empreendedores: perfil, dificuldades na gestão e perspectivas dos empreendimentos. In: ENCONTRO DE ESTUDOS SOBRE EMPREENDEDORISMO E GESTÃO DE PEQUENAS EMPRESAS, 4., 2005, Curitiba, PR. Anais... 
Curitiba, 2005.

TEIXEIRA, R. M, DUCCI, N. P. C, SARRASSINI, N. S, MUNHE, V. P. C, DUCCI, L. Z.

Empreendedorismo jovem e a influência da família: a história de vida de uma empreendedora de sucesso. REGE, São Paulo - SP, Brasil, v. 18, n. 1, p. 3-18, jan./mar. 2011 